\title{
Study of Wind Turbine Aerodynamic Performance Using Numerical Methods
}

\author{
S. Derakhshan and A. Tavaziani
}

\begin{abstract}
Design of wind turbine blades strictly depends on high precision, reliable and robust numerical predictions of its performance in all of operation conditions. This paper aims to simulate the flow around horizontal wind turbine blade with Computational Flow Dynamics (CFD) using a validated 3D Navier-Stokes flow solver. The main objectives of this study are investigating of different turbulence models and aerodynamic performance of wind turbine blades. The NREL Phase VI rotor used for CFD simulations and testing. Three different turbulence models included of Spalart- Allmaras, k-epsilon (Launder Sharma) and k- $\omega$ SST tested and the best model for prediction of wind turbine performance is provided. Since Mach number is less than $\mathbf{0 . 3}$, the flow around wind turbine blade is incompressible and precondition used. For all cases the structure grid used for Fluid reticulation grid. For results more accuracy, use of preconditioning is necessary. Outputs of flow solver are $t$ power and pressure coefficients for each section. At the final the k-epsilon with preconditioning code is selected the best model for simulation of flow around wind turbine blades.
\end{abstract}

Index Terms-Computational fluid dynamics (CFD), horizontal wind turbine (HWT), aerodynamic design, turbulence models.

\section{INTRODUCTION}

CFD simulations have become an important part of applied projects. In turbo machines, imprecise solving of the flow field around the turbine causes incorrect calculation of the forces acting on the turbine and thus results economic losses.

Many methods proposed and applied for turbulent simulation in analysis of flow around turbo machines in computational flow dynamics. One of the most popular method for this object are Reynolds Averaged Navier- Stokes (RANS).

To simulate various problems, some models have a high degree of accuracy of predictions (e.g. separated flow, separation point, flow reattachment and other characteristics of flow) and one possible way for introducing the appropriate turbulence model is sensitivity analysis.

The main objectives of this study are investigating of different turbulence models and aerodynamic performance of wind turbine blades. The NREL Phase VI rotor is the test case for CFD simulations.

There are many approaches for flow simulations around wind turbine blade. The blade element momentum theory (BEM) is used due to its reliability and fastness in $2 \mathrm{D}$ simulations.

Limitation of this approach is that it's weak in modeling of

Manuscript received January 31, 2014; revised April 30, 2014

The authors are with Iran University of Science and Technology, Tehran, Irhm2431 Iran (e-mail: shderakhshan@iust.ac.ir, ali_tavaziani@mecheng.iust.ac.ir). three dimensional and rotational effects. The other limitation of this method is inability to simulate helical tip vortices and important characteristics of flow.

On the other hand, BEM method for calculate loads on each airfoil need to lift and drag verses angle of attach.

There is another method for analysis of flow used in design of wind turbine blades. Best example of these methods is Computational fluid dynamics (CFD) methods that has most accurate solving.

CFD methods solve the governing fluid dynamics equations of turbomachinery. Computational fluid dynamics (CFD) methods don't need to the data of lift and drag coefficients and able to simulate 3D dimensional flow fields. Major limitation of Computational fluid dynamics (CFD) methods is that computational time is more than the other approaches. CFD simulations studied in some projects.

Duque et al. [1] compared the accuracy of three approach include Blade element momentum method, vortex lattice method and Navier- Stokes simulations on phase II wind turbine in their research. Aerodynamic performance of Horizontal Axis Wind Turbine (HAWT) was investigated by Sorensen et al. [2] using Ellipsis code.

Zahle et al. [3] investigated unsteady effects of tower on blade. This work was done on National Renewable Energy Laboratory (NREL) Phase VI wind turbine and the solver was simulated 3D Navier- Stokes.

Postdam et al. [4] generated difference mesh densities and compared unstructured and structured meshes using 3D Navier- Stokes CFD simulation. In PHD thesis of Lynch [5], many unstructured meshes using CFD simulations were developed. Lanzafame et al. [6] simulated phase VI wind turbine with CFD and Ming-Chen [7] investigated aerodynamic performance of this turbine with finite element approach. In this paper, different models for study of Phase VI Horizontal Axis Wind Turbine (HAWT) aerodynamic performance used and different wind speeds studied. The flow around horizontal wind turbine blade simulated with Computational Flow Dynamics (CFD) using a validated 3D Navier-Stokes flow solver and the results of numerical studies compared with experimental results. In this research, three models included of Spalart- Allmaras, k- $\varepsilon$ (Launder Sharma), SST k- $\omega$ and a precondition approach presented by Hakimi are compared and the best model for simulations is selected.

\section{MODEL DESCRIPTION AND FORMATION}

The phase VI rotor is designed by Giguère and Selig [8] from 988 through 1999.This turbine power control is stall-regulated type.

All sections of this turbine have the S809 airfoil in 
different scales and angles. Phase VI wind turbine is a horizontal axis wind turbine which is upwind with tapered and non-linear twisted. The twist distribution is shown in picture 1 that indicates in $70 \%$ span and twist is zero (Fig. 1). In test of wind turbine a two blade configuration of this type with $5.029 \mathrm{~m}$ radiuses that operating with $72 \mathrm{rpm}$ as radial speed was used [9].

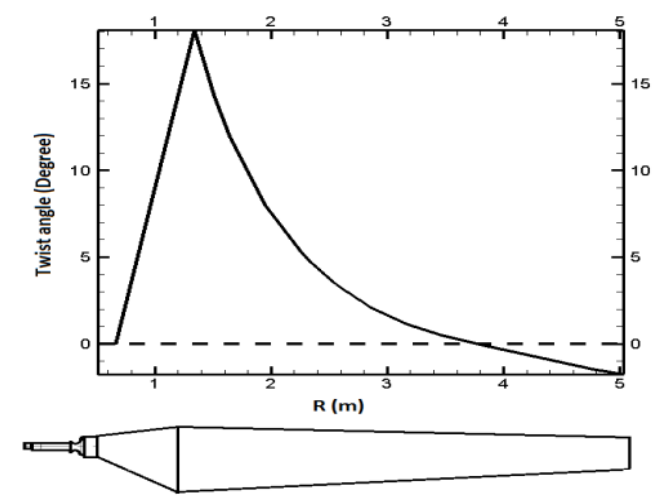

Fig. 1. Twist distribution.

A summary of the characteristics is shown in the Table I.

TABLE I: THE ARRANGEMENT OF CHANNELS

\begin{tabular}{|l|c|}
\hline Number of blades & 2 blade \\
\hline Rotor Diameter & $10.58 \mathrm{~m}$ \\
\hline Hub Height & $12.192 \mathrm{~m}$ \\
\hline Rotational Speed & $71.63 \mathrm{rpm}$ \\
\hline Cone angle & 0 degrees \\
\hline Power Regulation & Stall \\
\hline Blade tip pitch angle & 3 degrees \\
\hline Rotor location & Upwind \\
\hline Rotational Direction & CCW \\
\hline Twist angle & Non-linear twist along \\
\hline Airfoils & S809 in different scales and angles \\
\hline
\end{tabular}

Unsteady Aerodynamics Experiments was done in the 80 by 120 foot wind tunnel by National Renewable Energy Laboratory (NREl) in NASA Ames Research center.

For create geometry with these characteristics, first, control points at different sections were created then this control points were connected by B-spline carves. Comprehensive information about wind turbine geometry Phase 6 in [9] can be found. In Fig. 2 and Fig. 3 the designed blade is shown in different in various shots.

\section{MESH GENERATION}

A structured mesh around one blade and the surrounding air of turbine was generated and for other blade periodically repeated. With the aim of generating a structured hexahedral grid, the solution domain was divided into 16 component parts. As is shown in Fig. 7, the computational domain is six times the blade length in radial direction and 15 times the blade length in axial direction.

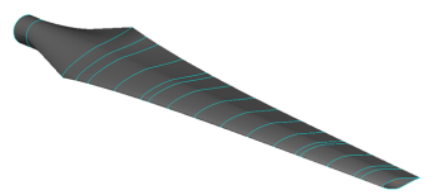

Fig. 2. 3D blade.

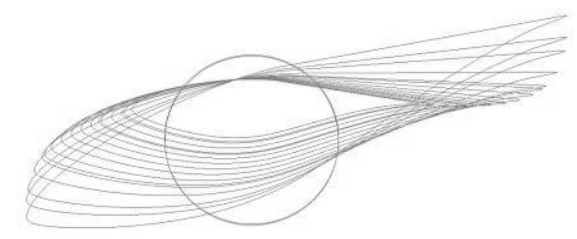

Fig. 3. Twist in blade.

Mesh is generated with structured grid of 2697136 nodes that 1527115 node of this is on blade and 1169621 node is around blade. The thickness of the first cell is $1 \times 10^{-5} \mathrm{~m} . y^{+}$ value in this case is 0.2 to 1.1 and due to the low Reynolds models used in this study, this range is suitable. Mesh contour is shown in Fig. 4 [10].

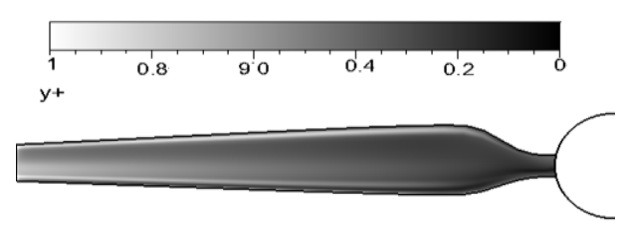

Fig. 4. $y^{+}$contoure

Mesh in blade-to-blade view, on blade and 3D mesh generation around blade is shown in Fig. 5, Fig. 6, and Fig. 7. The independence of wind turbines power from grid number was checked for blade geometry simulation as depicted in Fig. 8 . It was found that power varies by less than $0.05 \%$ for the blade when grid numbers are more than 1.2 million respectively.

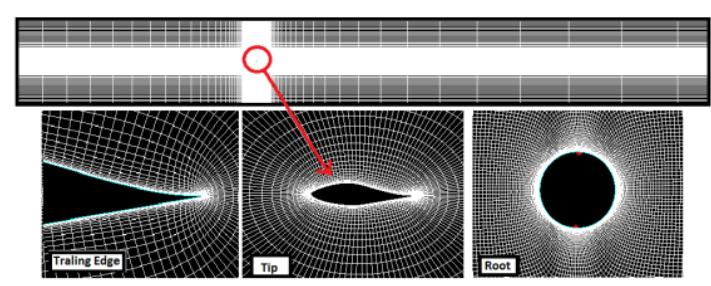

Fig. 5. Blade-to-blade view of mesh.



Fig. 6. Mesh generation on blade.

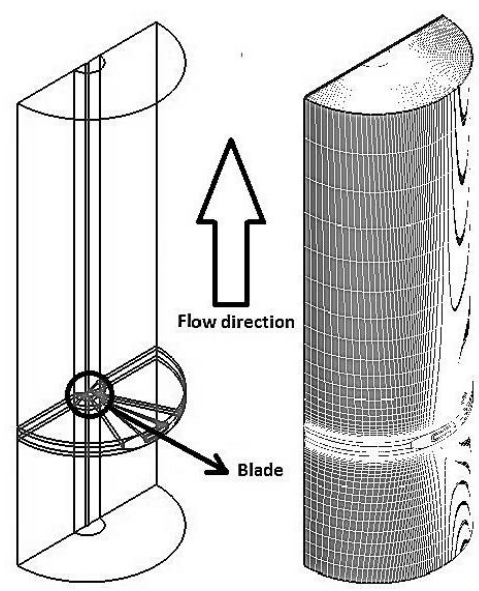

Fig. 7. 3D mesh on domain. 


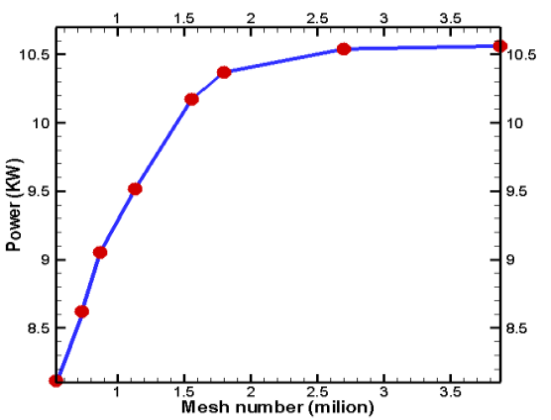

Fig. 8. Grid independency.

\section{NUMERICAL SIMULATION}

For reducing the computation, and because yaw system is not used in the wind turbine and due to the symmetry flow field, the grid generation was imposed on one blade but flow computation was solved on whole rotor with two blades.

To simulate and solve equations of flow around the blade, computational Flow Dynamics (CFD) using a validated 3D Navier-Stokes flow solver is used. It's based on finite volume discretization. The physical model used in solver is the Reynolds- Averaged Navier-Stokes equations in rotating frames of reference coupled with various turbulence models. Solves were done until convergence criterion satisfied and global residual decreased to less than $10 \mathrm{e}^{-5}$ for discretized equations.

\section{A. Investigation Reynolds Number}

Reynolds number for tip and root is shown in Table II. From this table, at all wind speeds, flow is turbulent.

TABLE II: REYNOLDS NUMBER FOR TIP AND ROOT
\begin{tabular}{|c|c|c|}
\hline Wind speed (m/s) & Tip & Root \\
\hline 5 & 937834.8 & 314063.2 \\
\hline 7 & 945496.8 & 397878.6 \\
\hline 10 & 961576 & 533956.6 \\
\hline 13 & 982911.5 & 675770.5 \\
\hline 15 & 999892.7 & 771945.4 \\
\hline 20 & 105192 & 1015385 \\
\hline
\end{tabular}

\section{B. The Governing Equations}

For Newtonian fluids in Cartesian coordinate, conservation equations of mass, momentum and energy which refer to (1) where $u_{i}$ is velocity in direction of $x_{i} . \mathrm{P}$ is static pressure, $\mathrm{H}$ is total enthalpy, $\rho$ is density, $\tau_{i j}$ is viscous stress tensor, $q_{j}$ is heat flux term and $\mathrm{S}$ is additional term added to source terms. $\mathrm{H}$ is total enthalpy and $\mathrm{h}$ is static enthalpy.

$$
\left\{\begin{array}{l}
\frac{\partial \rho}{\partial t}+\frac{\partial\left(\rho u_{j}\right)}{\partial x_{j}}=0 \\
\frac{\partial\left(\rho u_{i}\right)}{\partial t}+\frac{\partial\left(\rho u_{j} u_{i}\right)}{\partial x_{j}}=-\frac{\partial P}{\partial x_{i}}+\frac{\partial \tau_{i j}}{\partial x_{j}}+S_{u i} \\
\frac{\partial(\rho H)}{\partial t}-\frac{\partial P}{\partial t}+\frac{\partial}{\partial x_{j}}\left(\rho u_{j} H\right)=-\frac{\partial q_{j}}{\partial x_{j}}+\frac{\partial\left(u_{i} \tau_{i j}\right)}{\partial x_{j}}+S_{E}
\end{array}\right.
$$

Molecular flux $\tau_{i j}$ and $q_{j}$ are referred to (2) and (3) that $\mu, \lambda, \Gamma_{k} \cdot h_{k}$ and $Y_{k}$ respectively are dynamic viscosity, conduct coefficient, diffusion, static enthalpy and component mass. Second term in equation (3) denotes molecular distribution of energy.

$$
\begin{gathered}
\tau_{i j}=\mu\left(\frac{\partial u_{i}}{\partial x_{j}}+\frac{\partial u_{j}}{\partial x_{i}}\right)+\frac{2}{3} \mu \frac{\partial u_{l}}{\partial x_{l}} \delta_{i j} \\
q_{j}=-\lambda \frac{\partial T}{\partial x_{j}}-\sum_{k}^{n} \Gamma_{k} h_{k} \frac{\partial Y_{k}}{\partial x_{j}}
\end{gathered}
$$

Considering the turbulence models and writing State variables into a mean value and a fluctuating quantity, flow equations referred to (4) where $\mu_{\text {eff }}$ and $\mathrm{H}$ are referred to (5) and (6).

$$
\left\{\begin{array}{c}
\frac{\partial \rho}{\partial t}+\frac{\partial\left(\rho u_{j}\right)}{\partial x_{j}}=0 \\
\frac{\partial\left(\rho u_{i}\right)}{\partial t}+\frac{\partial\left(\rho u_{j} u_{i}\right)}{\partial x_{j}}=-\frac{\partial P}{\partial x_{i}}+\frac{\partial}{\partial x_{j}}\left\{\mu_{e f f}\left(\frac{\partial u i}{\partial x_{j}}+\frac{\partial u i}{\partial x_{j}}\right)\right\}+S_{u i} \\
\frac{\partial(\rho H)}{\partial t}-\frac{\partial P}{\partial t}+\frac{\partial\left(\rho u_{j} H\right)}{\partial x_{j}}=\frac{\partial}{\partial x_{j}}\left(\lambda \frac{\partial T}{\partial x_{i}}+\frac{\mu_{t}}{\operatorname{Pr}_{t}} \frac{\partial h}{\partial x_{j}}\right) \\
+\mathrm{S}_{E} \frac{\partial}{\partial x_{j}}\left\{u_{i}\left[\begin{array}{c}
\left.\mu_{e f f}\left(\frac{\partial u i}{\partial x_{j}}+\frac{\partial u i}{\partial x_{j}}\right)-\frac{2}{3} \mu_{e f f} \frac{\partial u_{l}}{\partial x_{l}} \delta_{i j}\right]+\mu \frac{\partial k}{\partial x_{j}}
\end{array}\right\}\right. \\
H=h+\frac{1}{2} u_{i} u_{j}+k \\
\mu_{\text {eff }}=\mu+\mu_{t}
\end{array}\right.
$$

Three turbulence models were used in this study. First model is one equation model called Spalart- Allmaras.

The Spalrt- Allmaras model uses only one additional equation to model turbulence viscosity transport.

This model is suitable for low Reynolds numbers and is useful for its robustness and treat complex flow characteristics. This model proposed for aerospace applications and is a general model for turbomachinery.

The SST k- $\omega$ model provided for combination of $k-\omega$ formula in wall reigns with $\mathrm{k}-\varepsilon$ model in regions away from the wall so has all the advantages of the two models and is used in a wide range of problems.

The $\mathrm{k}-\varepsilon$ model is semi-empirical model that used widely in industrial problem Due to its economical and reasonable accuracy.

k- $\varepsilon$ Launder Sharma is a low Reynolds model. It's a good method for flows that standard model hasn't suitable accuracy. In this study $y^{+}$is between 0.2 to 1.1 , so k- $\varepsilon$ launder Sharma turbulence model is used.

In the low Mach number regimes, algorithms designed for compressible flows have low efficiency. The difficulty is in applying compressible codes for low Mach number. When flow velocity is low in comparison with acoustic speeds, the codes converge slowly.

Low Mach numbers, the need for development of 
preconditions for more accurate solves and fast convergence increases.

In this study, Hakimi precondition for this purpose has been used [11].

\section{Flow Simulation}

Three dimensional Navier- Stokes and RANS equations solved on the blade. Three turbulence models used for comparing that includes Spalart- Allmaras, k- $\varepsilon$ (Launder Sharma) and SST k- $\omega$. Results selected from [12]. Results of simulation with this models, accuracy and comparison between experimental and three turbulence models are shown in Fig. 9 and value of errors are in Table III.



Fig. 9. Comparison of experimental power and computed power.

TABLE III: COMPUTATION POWER WITH MODELS AND CORRESPONDING

\begin{tabular}{|c|c|c|c|c|}
\hline $\begin{array}{c}\text { Wind speed } \\
(\mathrm{m} / \mathrm{s})\end{array}$ & SA power & SA Error & $\begin{array}{c}\text { SST K- } \omega \\
\text { power }\end{array}$ & SST k- $\omega$ Error \\
\hline 5 & 2.38 & $3.92 \%$ & 2.46 & $7.32 \%$ \\
\hline 7 & 5.58 & $7.54 \%$ & 6.82 & $12.95 \%$ \\
\hline 10 & 10.93 & $8.19 \%$ & 11.85 & $17.31 \%$ \\
\hline 13 & 8.81 & $10.81 \%$ & 10.93 & $10.67 \%$ \\
\hline 15 & 7.66 & $14.23 \%$ & 6.46 & $27.62 \%$ \\
\hline 20 & 7.54 & $9.22 \%$ & 6.06 & $26.04 \%$ \\
\hline
\end{tabular}

\begin{tabular}{|c|c|c|c|}
\hline $\begin{array}{c}\text { Wind speed } \\
(\mathrm{m} / \mathrm{s})\end{array}$ & $\begin{array}{c}\mathrm{k}-\varepsilon \text { Launder } \\
\text { Sharma } \\
\text { power }\end{array}$ & $\begin{array}{c}\mathrm{k}-\varepsilon \text { Launder } \\
\text { Sharma } \\
\text { Error }\end{array}$ & $\begin{array}{c}\text { EXP data } \\
\text { power }(\mathrm{kw})\end{array}$ \\
\hline 5 & 2.22 & $3.16 \%$ & 2.29 \\
\hline 7 & 5.82 & $3.61 \%$ & 6.04 \\
\hline 10 & 10.54 & $4.34 \%$ & 10.10 \\
\hline 13 & 9.21 & $6.74 \%$ & 9.88 \\
\hline 15 & 8.13 & $8.83 \%$ & 8.92 \\
\hline 20 & 7.62 & $7.07 \%$ & 8.2 \\
\hline
\end{tabular}

If $U_{\infty}$ is wind speed in terms of $\mathrm{m} / \mathrm{s}, r$ is radius of section from center of hub in terms of $\mathrm{m}, \Omega$ is the rotational speed in terms of $\mathrm{rad} / \mathrm{s}$ and $p_{\infty}$ is density of free stream (wind speed) in terms of $\mathrm{kg} / \mathrm{m}^{3}$ so pressure coefficient is calculated from:

$$
C_{p}=\frac{\left(p-p_{\infty}\right)}{0.5 p_{\infty}\left(U_{\infty}^{2}+(\Omega r)^{2}\right.}
$$

In Fig. 10, Fig. 11, and Fig. 12, pressure coefficients from numerical calculations with different turbulence models are compared. Pressure coefficients are computed with CFD using three turbulence models and compared with experimental data at 3 wind speed; include 7, 10, and $15 \mathrm{~m} / \mathrm{s}$ in 5 sections of 3D blade, $30 \%, 47 \%, 63 \%, 80 \%$, and $95 \%$.
Experimental results have been extracted from [12].
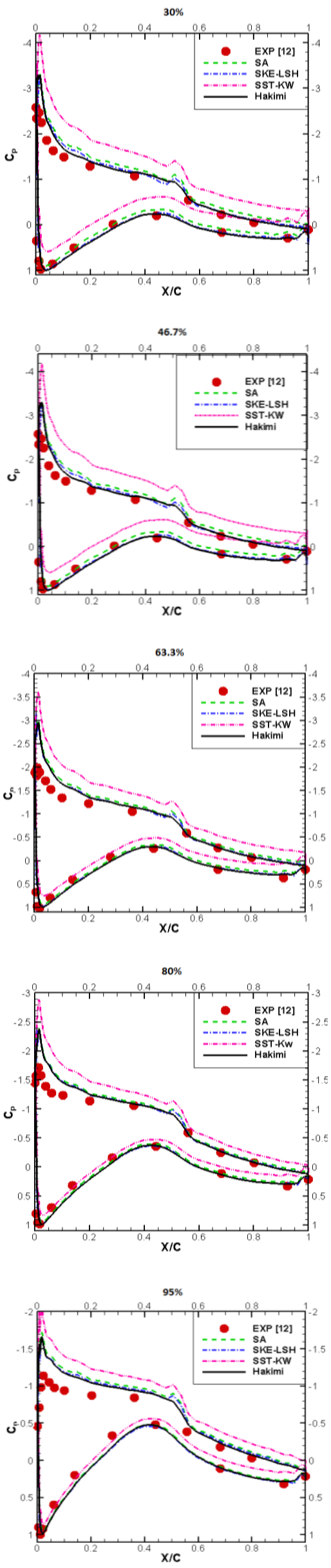

Fig. 10. Comparison pressure coefficient between experimental and numerical in $7 \mathrm{~m} / \mathrm{s}$ wind speed. 

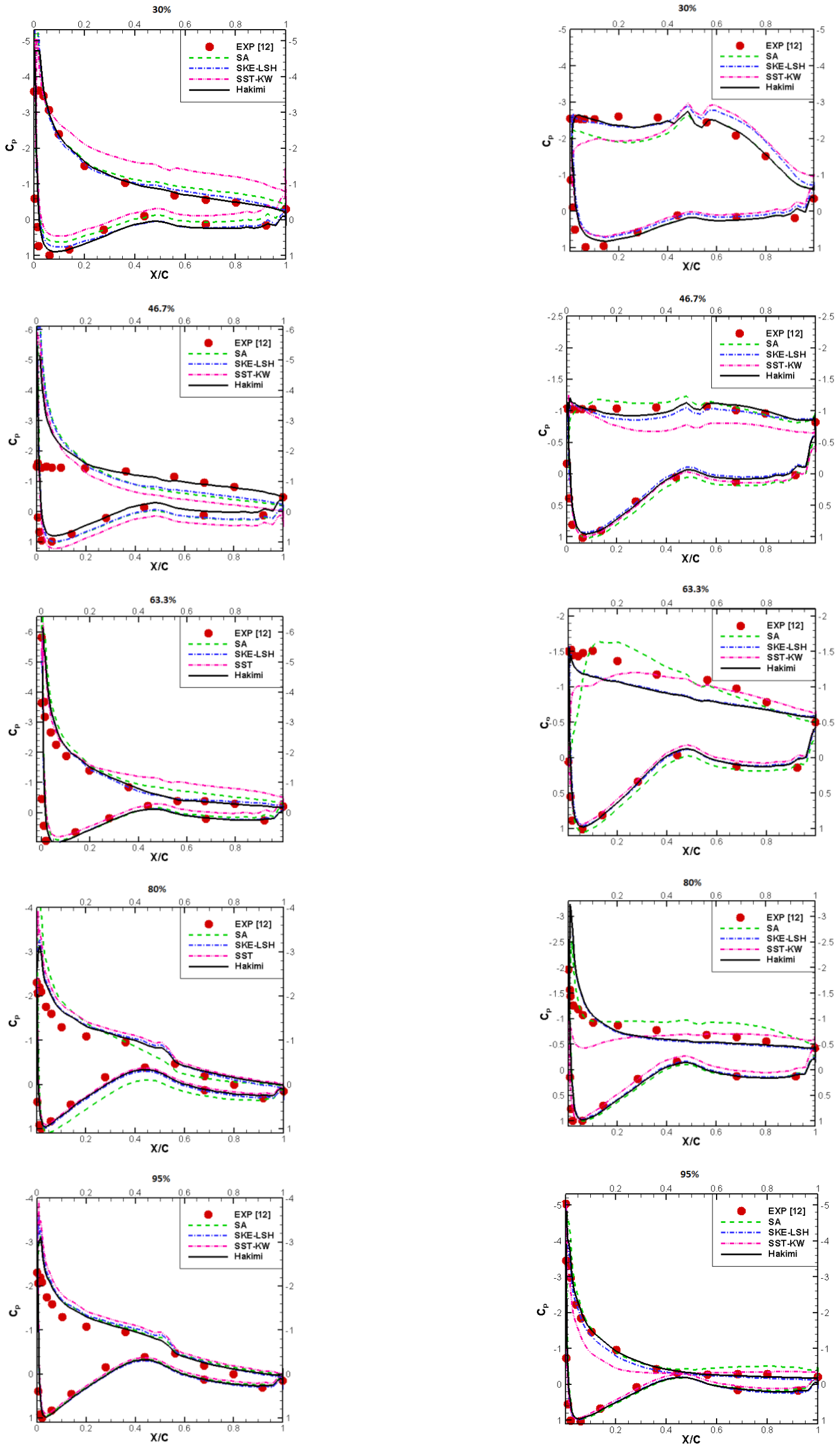

Fig. 11. Comparison pressure coefficient between experimental and numerical in $10 \mathrm{~m} / \mathrm{s}$ wind speed.

Fig. 12. Comparison pressure coefficient between experimental and numerical in $15 \mathrm{~m} / \mathrm{s}$ wind speed. 
In Fig. 13, Fig. 14, and Fig. 15, pressure contours in three speeds 7,10 , and 15 on suction and pressure sides are shown:


Fig. 13. Pressure contours for Spalart - Allmaras model
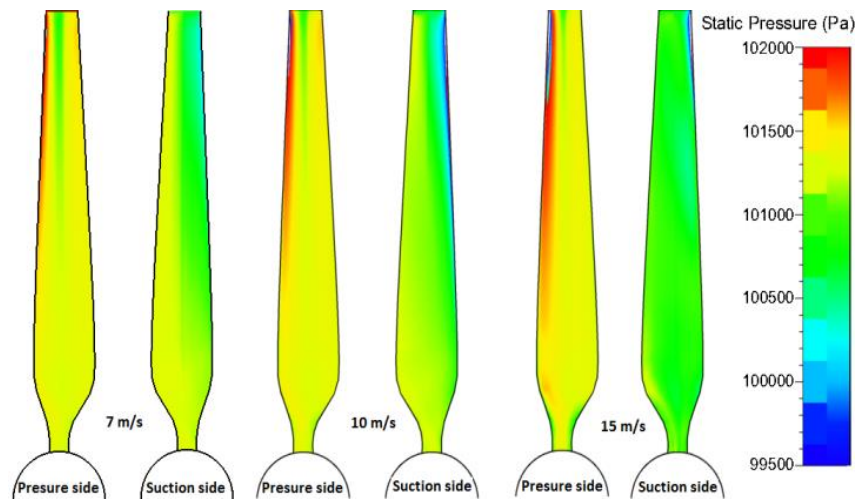

Fig. 14. Pressure contours for k- $\varepsilon$ model.
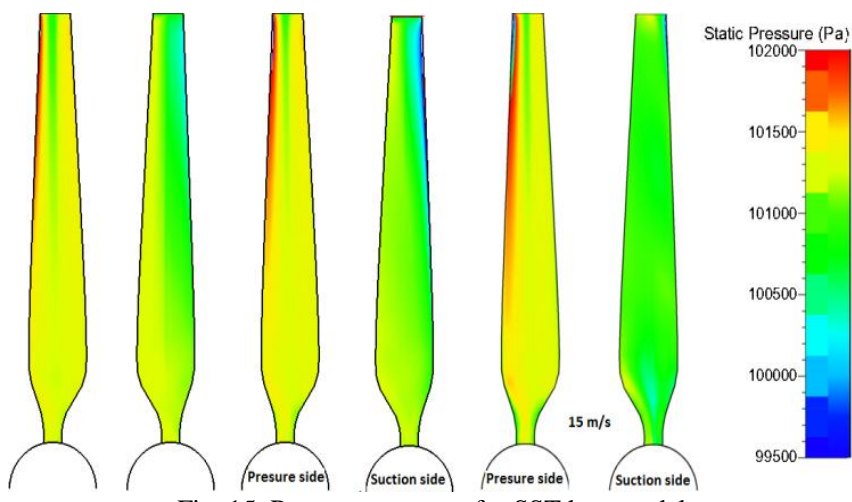

Fig. 15. Pressure contours for SST k- $\omega$ model

According to pressure contours a considerable variation from leading edge to trailing edge and from root to tip in both suction and pressure sides are occurs.

In Fig. 16, Fig. 17, and Fig. 18 related speed contours in investigated sections, in different speeds and for $k-\varepsilon$ turbulence model are shown. The other models not showed in the results because of not to make the figures crowded.

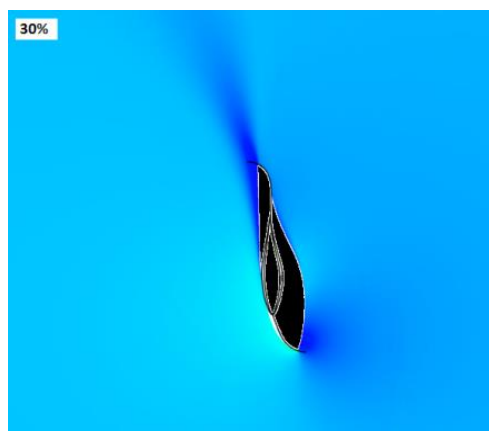

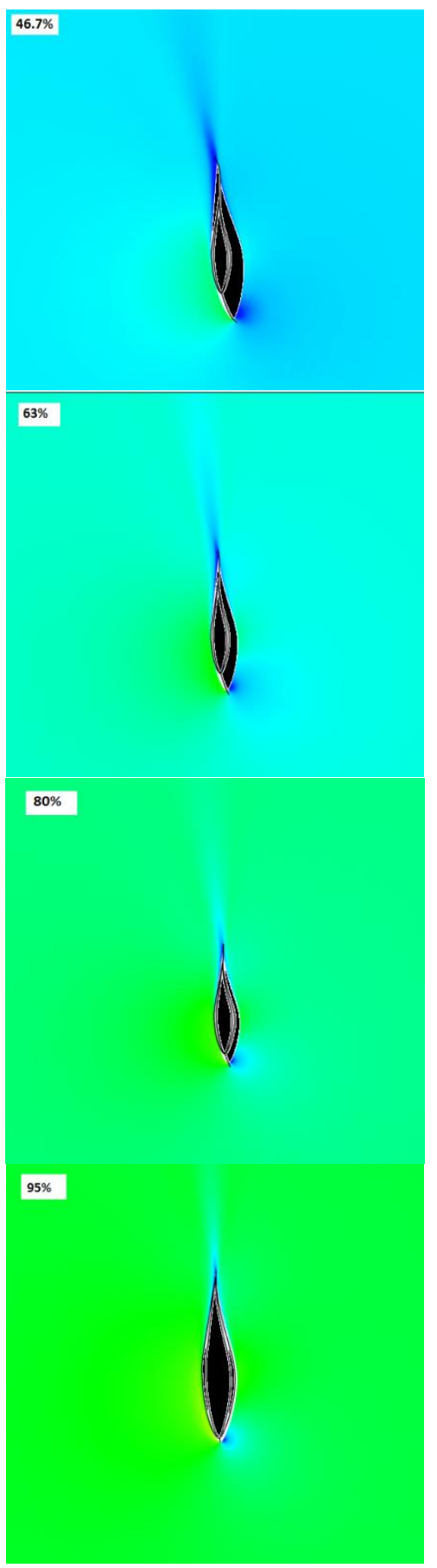

Fig. 16. Contours of relative velocity at $7 \mathrm{~m} / \mathrm{s}$ for $\mathrm{k}-\varepsilon$ model.

Based on Fig. 9 at 5 to 10 wind speeds (low speeds) three turbulence models have similar predictions in power.

At higher speeds (10 to 20) $\mathrm{k}-\varepsilon$ (Launder Sharma) turbulence model predicted the actual results with more accuracy and has best agreements with experimental so it's best between three models.

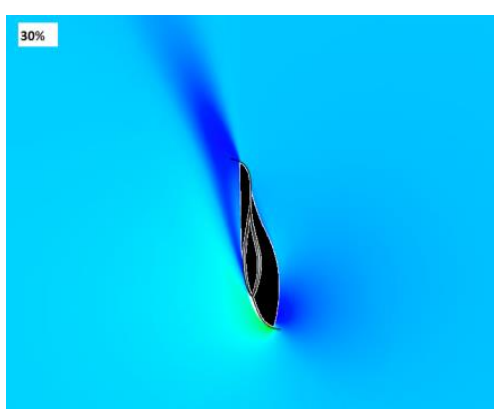




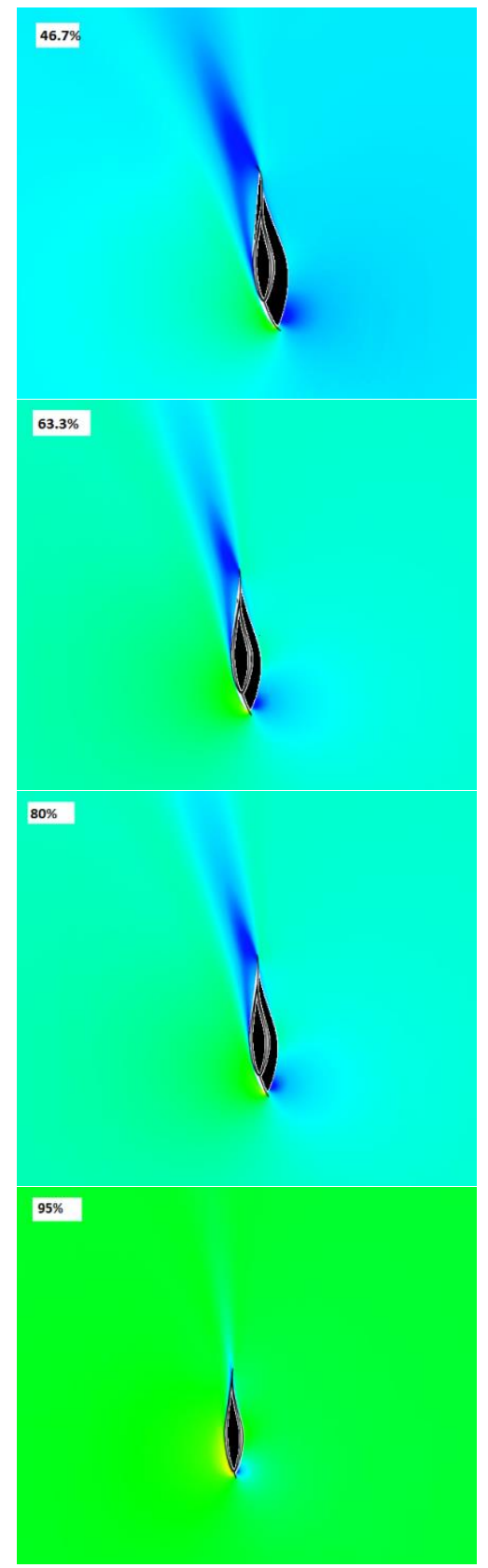

Fig. 17. Contours of relative velocity at $10 \mathrm{~m} /$ for $\mathrm{k}-\varepsilon$ model.

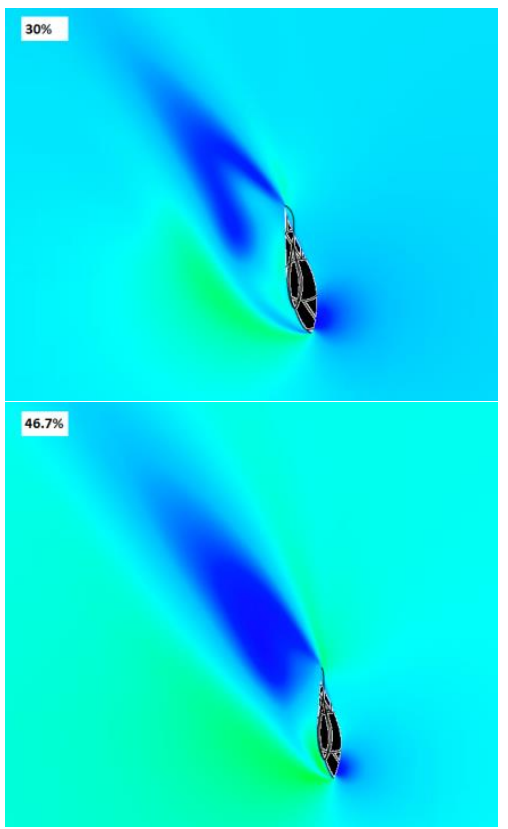

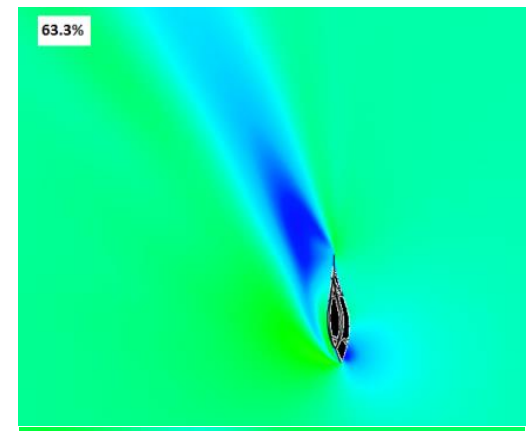

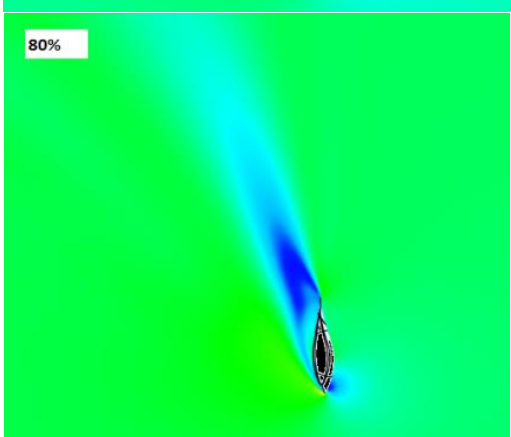

$95 \%$

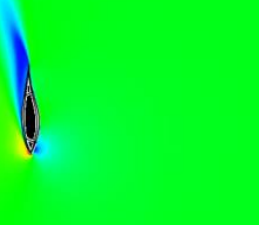

Fig. 18. Contours of relative velocity at $15 \mathrm{~m} / \mathrm{s}$ for k- $\varepsilon$ model.

According to results and comparisons, $\mathrm{k}-\varepsilon$ (Launder Sharma) is suitable for calculation of horizontal axis wind turbine (HAWT) power in low, medium and high speeds. According to studies it was predicted that the SST k- $\omega$ has better accuracy in prediction of performance of wind turbine rotor.

For more accuracy in two equation turbulence models like $\mathrm{k}-\omega \mathrm{SST}$, the grid must arrangement on normal direction. Reference [13] studies on different turbulence models. It shows high sensitivity of $\mathrm{k}-\varepsilon$ to $y^{+}$while SST k- $\omega$ and Spalart- Allmaras have less sensitivity. But this study was done on a flat plate.

Comparisons between two turbulence models include Spalart- Allmaras and SST k- $\omega$ investigated in [14] and the results showed the superior results of Spalart- Allmaras method.

In other study in [15] some models including two equation turbulent models which is investigated in this paper are compared. This study was on a blade of National Renewable Energy Laboratory (NREL) phase III that hasn't twist. Two turbulence models was $\mathrm{k}-\varepsilon$ and SST k- $\omega$. The results showed that $\mathrm{k}-\varepsilon$ has best prediction similar to this paper.

Reference [6] blade of Phase VI wind turbine is simulated using FLUENT software and the turbulence model was SST $\mathrm{k}-\omega$. The results of this study shows inability of this turbulence model in prediction of wind turbine flow characteristics. Also according to the section IV-A and low Reynolds on turbine blades, excellence of $\mathrm{k}$-e Launder Sharma is predictable. 
The figures of pressure coefficients show considerable agreement with experimental data. May noticed that some of the figures show large differences between results of numerical and experimental. By investigated the velocity contours and pressure coefficients at that section and speed, a separation occur. The separation causes large vorticities and it's hard for the turbulence models that investigated in this paper to capture those. In the velocity contours, the blue regains after airfoils show separation and vorticites.

Velocity in sections of blade is calculated by $v=\sqrt{U^{2}+(\Omega r)}$ that $\mathrm{U}$ is wind speed, $\Omega$ is rotational speed and $\mathrm{r}$ is radius of section.

For $7 \mathrm{~m} / \mathrm{s}$, velocity at $30 \%$ span is $13.36 \mathrm{vm} / \mathrm{s}$ and related Mach number is 0.0389 . At $95 \%$ span, velocity and Mach number are $36.04 \mathrm{~m} / \mathrm{s}$ and 0.105 . For wind speed of $15 \mathrm{~m} / \mathrm{s}$, velocity at $30 \%$ span is equal to $18.826 \mathrm{~m} / \mathrm{s}$ and Mach number is 0.056 . At $95 \%$ span velocity and Mach number are $39.021 \mathrm{~m} / \mathrm{s}$ and 0.114 .

According to Mach number of each section and comparison of numerical results of Hakimi approach and experimental results, use of Hakimi approach increase accuracy of predictions specially in low speeds. The reason is application of precondition approach for low Mach number so since Mach number of root is less than tip, effect of precondition approach is major.

\section{CPU CosT}

The corresponding computation time has been presented in Table IV the processes were done using a PC computer with 4 GB of RAM memory, Core 2 and $2.5 \mathrm{GHZ}$ of speed.

TABLE IV: REYNOLDS NUMBER FOR TIP AND ROOT

\begin{tabular}{|c|c|c|c|}
\hline Process & $\begin{array}{c}\text { CPU time for } \\
\text { one process }\end{array}$ & $\begin{array}{c}\text { Number } \\
\text { Of process }\end{array}$ & $\begin{array}{c}\text { Total CPU } \\
\text { time }\end{array}$ \\
\hline Grid independency & 8 hour & 8 & 64 hour \\
\hline SA model & 10 hour & 3 & 30 hour \\
\hline K- $\varepsilon$ model & 15 hour & 3 & 45 hour \\
\hline SST k- $\omega$ model & 20 hour & 3 & 60 hour \\
\hline $\begin{array}{c}\text { Hakimi approach with } \\
\text { k- } \varepsilon\end{array}$ & 13 hour & 3 & 39 hour \\
\hline Total & \multicolumn{4}{|l}{238 hour } \\
\hline
\end{tabular}

\section{CONCLUSION}

Aerodynamic performance of Phase VI wind turbine was investigated.

Flow around wind turbine was simulated with Navier-Stokes equations using three difference turbulence models and results compared with experimental data.

To simplify the problem and due to the symmetry flow field, mesh was generated on one blade and similar mesh on other blades extended.

To increase the mesh density in important fields, computation domain was divided to 16 component parts.

For simulation of flow around wind turbine blade, NavierStokes equation used with different turbulence models include Spalart- Allmaras, k- $\varepsilon$ and SST k- $\omega$.

According to numerical results, at 5 to 10 wind speeds (low speeds) three turbulence models have similar predictions in power but at higher wind speeds $\mathrm{k}-\varepsilon$ has predicted with more accuracy, so it's best between three models.

Some of the figures showed large differences in prediction and experiment results. The reason is the separation causes large vorticities and it's hard for the turbulence models that investigated in this paper to capture those.

Mach number for the wind turbine was low so for more accuracy, use of precondition was seemed helpful. In this paper Hakimi precondition was used and results showed good agreement with actual data. Finally for prediction of performance of horizontal axis wind turbine, $\mathrm{k}-\varepsilon$ Launder Sharma turbulence model using Hakimi precondition is suggested.

\section{REFERENCES}

[1] E. Duque, C. V. Dam, and S. Hughes, "Navier-stokes simulations of the NREL combined experiment phase II rotor," presented at the 37th Aerospace Sciences Meeting and Exhibit, American Institute of Aeronautics and Astronautics, Reno, NV,U.S.A. January 1999.

[2] N. N. Sørensen, "CFD modelling of laminar-turbulent transition for airfoils and rotors using the $\gamma$ - model," Wind Energy, vol. 12, no. 8, pp. 715-733, 2009.

[3] F. Zahle, N. N. Sørensen, and J. Johansen, "Wind turbine rotor-tower interaction using an incompressible overset grid method," Wind Energy, vol. 12, no. 6, pp. 594-619, 2009.

[4] M. A. Potsdam et al., "Unstructured mesh CFD aerodynamic analysis of the NREL Phase VI rotor," presented at the 47th AIAA Aerospace Sciences Meeting, Orlando, Florida, U.S.A. January 2009.

[5] C. E. Lynch, Advanced CFD Methods for Wind Turbine Analysis, 2011.

[6] R. Lanzafame et al., "Wind turbine CFD modeling using a correlationbased transitional model," Renewable Energy, vol. 52, pp. 31-39, 2013.

[7] M. C. Hsu, I. Akkerman, and Y. Bazilevs, "Finite element simulation of wind turbine aerodynamics: validation study using NREL Phase VI experiment," Wind Energy, 2013

[8] P. Giguere et al., "Design of a tapered and twisted blade for the NREL combined experiment rotor," NREL/SR, vol. 500, pp. 26173, 1999.

[9] M. M. Hand et al., "Unsteady aerodynamics experiment phase VI: wind tunnel test configurations and available data campaigns," NREL/TP, vol. 500, pp. 29955, 2001.

[10] User Мапиа, NUMECA, 2013.

[11] N. Hakimi, Preconditioning Methods for Time Dependent Navier Stoks Equations, 1997.

[12] M. M. Yelmule and E. A. Vsj, "CFD predictions of NREL Phase VI rotor experiments in NASA/AMES wind tunnel," International Journal of Renewable Energy Research, vol. 3, no. 2, pp. 261-269, 2013.

[13] P. G. Huang, J. E. Bardina, and T. J. Coakley, "Turbulence Modeling Validation, Testing, and Development," NASA Technical Memorandum, 1997.

[14] S. Benjanirat, "Computational studies of the horizontal axis wind turbines in high wind speed condition using advanced turbulence models," Ph.D. dissertation, School of Aerospace Engineering. Georgia Institute of Technology, 2006.

[15] A. Gupta, "Prediction of aerodynamic forces on wind turbine blades using computational fluid dynamics," Ph.D. dissertation, Applied Science in Industrial Systems Engineering. University of Regina, 2007.

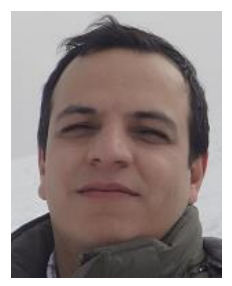

S. Derakhshan was born in Shahrekord, Iran on Sep. 11, 1978. He received $\mathrm{PhD}$ degree in mechanical engineering from University of Tehran, Tehran, Iran, 2008.

He is working as an assistant professor in School of Mechanical Engineering, Iran University of Science \& Technology (IUST), since 2010, January. He was also an invited lecturer at University of Tehran and University of Power and Technology, Tehran, Iran in 2009. In addition, he was a visiting professor in Jiangsu University, September 2010. He has taught some courses in the field of Fluid Mechanics, CFD, Renewable Energy and Hydraulic Turbomachinery.

$\mathrm{He}$ has published more than 20 papers in peer review journals and presented more than 10 papers in international conferences. He also published one book entitle" Renewable Energy" in Persian.

Dr. Derakhshan has awarded 22th Khwarizmi International Award (2008, Tehran, Iran). 